\title{
Análise da distribuição de royalties minerais aos municípios afetados pela atividade de mineração: Implicações no desenvolvimento socioeconômico de Barcarena, Pará,
} Brasil

\author{
Analysis of the distribution of mineral royalties to municipalities affected by mining activity: \\ Implications for the socioeconomic development of Barcarena, Pará, Brazil \\ Análisis de la distribución de regalías mineras a municipios afectados por la actividad minera: \\ Implicaciones para el desarrollo socioeconómico de Barcarena, Pará, Brasil
}

Recebido: 29/06/2021 | Revisado: 06/07/2021 | Aceito: 11/07/2021 | Publicado: 22/07/2021

\author{
Thamires Beatriz dos Santos Caitano \\ ORCID: https://orcid.org/0000-0002-7538-4366 \\ Universidade do Estado do Pará, Brasil \\ E-mail: thamirescaitano@hotmail.com \\ Mônica Moraes Ribeiro \\ ORCID: https://orcid.org/0000-0001-6310-557X \\ Universidade Federal do Pará, Brasil \\ E-mail: profa.monica.mr@gmail.com \\ Gundisalvo Piratoba Morales \\ ORCID: https://orcid.org/0000-0002-5930-7053 \\ Universidade do Estado do Pará, Brasil \\ E-mail: gundymorales@gmail.com
}

\begin{abstract}
Resumo
A partir da Lei $\mathrm{n}^{\circ}$ 13.540, de 18 de dezembro de 2017, os municípios impactados pela atividade de mineração passaram a ser beneficiados com a Compensação Financeira pela Exploração de Recursos Minerais (CFEM), os royalties minerais. Diante disso, o objetivo deste artigo é analisar o potencial de contribuição da CFEM no desenvolvimento socioeconômico do município de Barcarena, situado no estado do Pará, o qual é impactado pela logística de grandes projetos de mineração. A metodologia utilizada no estudo consistiu em pesquisa bibliográfica, análise da legislação brasileira, além de coleta e análise de dados da CFEM disponibilizados pela Agência Nacional de Mineração (ANM). Os resultados apontam que durante o período de abril de 2019 a abril de 2021, a prefeitura municipal de Barcarena recebeu $\mathrm{R}$ \$3.840.920,74 de compensação financeira, dado que está localidade é afetada pela presença de minerodutos e operações portuárias em seu território. Estes valores são pouco significativos se comparados aos recebidos pelos principais municípios produtores de minério na Amazônia brasileira. Ocorre que há pouca transparência em relação às políticas e destinações que estão sendo dadas a estes recursos pelos governantes locais. Além disso, a sociedade não participa das tomadas de decisões sobre a aplicação deste importante instrumento para o desenvolvimento local. Sendo assim, pode-se concluir que é necessário o planejamento e execução de políticas públicas na promoção do desenvolvimento socioeconômico de Barcarena, além do fomento a verticalização das cadeias produtivas minerais para maior geração de emprego e renda, e na diversificação econômica do município.
\end{abstract}

Palavras-chave: Amazônia brasileira; Mineração; Impactos socioambientais; CFEM; Desenvolvimento Local.

\begin{abstract}
As of Law $N^{\circ} 13,540$, of December 18, 2017, municipalities impacted by the mining activity started to benefit from the Financial Compensation for the Exploitation of Mineral Resources (CFEM), mineral royalties. Therefore, the aim of this article is to analyze the potential contribution of CFEM in the socioeconomic development of the municipality of Barcarena, located in the state of Pará, which is impacted by the logistics of large mining projects. The methodology used in the study consisted of bibliographic research, analysis of Brazilian legislation, in addition to the collection and analysis of CFEM data provided by the National Mining Agency (ANM). The results show that during the period from April 2019 to April 2021, the municipal government of Barcarena received R \$3,840,920.74 in financial compensation, as it location is affected by the presence of pipelines and port operations in its territory. These amounts are insignificant compared to those received by the main ore producing municipalities in the Brazilian Amazon. It turns out that there is little transparency in relation to the policies and destinations that are being given to these resources by local governments. Furthermore, society does not participate in decision-making on the application of this important instrument for local development. Therefore, it can be concluded that it is necessary to plan and implement public policies to promote the socioeconomic development of Barcarena, in addition to promoting the
\end{abstract}


verticalization of mineral production chains for greater employment and income generation, and in economic diversification of the municipality.

Keywords: Brazilian Amazon; Mining; Socio-environmental impacts; CFEM; Local Development.

\begin{abstract}
Resumen
A partir de la Ley n. ${ }^{\circ} 13.540$, del 18 de diciembre de 2017, los municipios impactados por la actividad minera pasaron a beneficiarse de la Compensación Financiera por la Explotación de Recursos Minerales (CFEM), regalías minerales. Por tanto, el objetivo de este artículo es analizar la potencial contribución de la CFEM en el desarrollo socioeconómico del municipio de Barcarena, situado en el estado de Pará, e impactado por la logística de grandes proyectos mineros. La metodología utilizada en el estudio consistió en la investigación bibliográfica, análisis de la legislación brasileña, además de la recolección y análisis de datos de CFEM proporcionados por la Agencia Nacional de Minería (ANM). Los resultados muestran que, durante el período de abril de 2019 a abril de 2021, el municipio de Barcarena recibió R \$ 3.840.920,74 por compensación económica, ya que esta ubicación se ve afectada por la presencia de ductos y operaciones portuarias en su territorio. Estos valores son insignificantes en comparación con los valores recibidos por los principales municipios productores de minerales de la Amazonía brasileña. Los resultados muestran que hay poca transparencia en relación a las políticas y destinos que le están dando los gobiernos locales a estos recursos, donde la sociedad no participa de la toma de decisiones sobre la aplicación de este importante instrumento para el desarrollo local. Por tanto, se puede concluir que es necesario planificar e implementar políticas públicas para promover el desarrollo socioeconómico de Barcarena, además de promover la verticalización de las cadenas de producción minera para una mayor generación de empleo y renta, y en la diversificación económica del municipio.
\end{abstract}

Palabras clave: Amazonia brasileña; Minería; Impactos socioambientales; CFEM; Desarrollo local.

\title{
1. Introdução
}

As atividades de extração e transformação industrial de minerais na Amazônia Oriental brasileira têm ocorrido desde meados do século XX (Siqueira-Gay, Sounter \& Sánchesz, 2020). Este trajeto histórico foi revestido por expectativas de modernização e desenvolvimento local em diversos segmentos sociais (Hauradou \& Amaral, 2019). Tais expectativas justificaram a implementação de ações estatais para favorecer a exploração industrial de minérios na região, impulsionadas pela demanda global de commodities minerais (Amaral \& Hauradou, 2020; Pereira et al., 2020).

É incontestável afirmar que a atividade minerária seja fundamental para o desenvolvimento das sociedades em seus mais diversos setores produtivos, constituindo-se em setor base de sustentação dos poderes econômicos e políticos (Dotsenko \& Ezdina, 2018). Entretanto, nos municípios paraenses onde ocorrem a extração mineral, bem como naqueles impactados por sua logística, tal atividade não tem promovido o desenvolvimento local de maneira adequada e sim ocasionando grandes impactos socioambientais, perpetuando o cenário de danos, conflitos e insegurança que comprometem o bem estar social (Karídio \& Talbot, 2020; Lemos \& Pimentel, 2021).

$\mathrm{Na}$ busca de mitigar essas contradições, foi estabelecido que as empresas mineradoras que atuam no Brasil devem pagar à União uma Compensação Financeira pela Exploração dos Recursos Minerais (CFEM), os chamados royalties da mineração, conforme o previsto na Constituição Federal Brasileira de 1988. As regras de recolhimento e distribuição da CFEM tiveram algumas alterações pela Lei $n^{\circ}$ 13.540, de 18 de dezembro de 2017, as quais destaca-se o direito de alguns municípios receberem recursos da CFEM por serem efetivamente afetados pela logística da exploração mineral que ocorre em outros municípios, onde as atividades minerárias promovem danos socioambientais (Martins, 2020).

Os municípios do estado do Pará, impactados pela logística da atividade de mineração, apresentam fortes características de favelização e subdesenvolvimento (Medeiros, Medeiros \& Medeiros, 2018; Silva \& Chagas, 2020). Dentre eles, encontra-se o município de Barcarena, que tem sido cenário de implantação de grandes projetos industriais, portuários e de logística desde a década de 1980 (Nazaré, Nascimento \& Penha, 2019). Este município apresenta infraestrutura logística para escoamento de commodities, além de um intenso processo de atividade industrial, onde se destacam empresas de mineração multinacionais que atuam no mercado internacional (Hazeu \& Rodrigues, 2019). 
O município de Barcarena, tem sido destino final de minerodutos que transportam minério de alumínio e caulim extraídos em outros municípios, além de operações de transformação mineral e operações portuárias de escoamento de minérios, principalmente para o mercado externo, que tem ocasionado impactos ao meio ambiente e na qualidade de vida da população local (Carmo, 2020). Diante disso, este estudo tem como objetivo analisar os royalties minerais distribuídos ao município de Barcarena, visto que este é afetado pela atividade de mineração, tencionando o seu papel na promoção do desenvolvimento socioeconômico local.

\subsection{Royalties da Mineração no Brasil}

No Brasil, a Compensação Financeira pela Exploração de Recursos Minerais (CFEM) foi instituída pela Lei nº 7.990 , de 28 de dezembro de 1989, como uma contraprestação paga pelas empresas mineradoras pelo aproveitamento econômico dos recursos minerais em território brasileiro, sendo devida aos Estados, Distrito Federal, Municípios e aos órgãos da administração da União. A Lei n ${ }^{\circ}$ 8.001, de 13 de março de 1990, definiu os percentuais da distribuição da compensação financeira entre os entes federativos.

A Agência Nacional de Mineração (ANM) é quem fiscaliza, recolhe e distribui as receitas oriundas da CFEM de acordo com o estabelecido na Lei $\mathrm{n}^{\mathrm{o}}$ 13.540, de 18 de dezembro de 2017, a qual alterou as regras presentes nas Leis $\mathrm{n}^{\circ}$ 7.990/1989 e nº 8.001/1990, como a sua incidência, a base de cálculo, as alíquotas minerais e a sua distribuição entre os entes federativos (Brasil, 2017). Sendo assim, a CFEM passou a ser calculada sobre a receita bruta de venda do minério, onde é deduzido apenas os tributos que incidem sobre a sua comercialização, e as alíquotas atuais variam de $1 \%$ a 3,5\% dependendo da substância mineral explorada (Quadro 1).

Quadro 1. Alíquotas para fins de incidência da CFEM.

\begin{tabular}{|c|l|}
\hline Alíquota & Substância Mineral \\
\hline $3,5 \%$ & Ferro, conforme a Lei pode variar entre 3,5\% a 2\% \\
\hline $3 \%$ & Bauxita, manganês, nióbio e sal-gema \\
\hline $2 \%$ & Diamante e demais substâncias minerais \\
\hline $1,5 \%$ & Ouro \\
\hline $1 \%$ & $\begin{array}{l}\text { Rochas, areias, cascalhos, saibros e demais substâncias minerais quando destinadas ao } \\
\text { uso imediato na construção civil; rochas ornamentais; águas minerais e termais }\end{array}$ \\
\hline
\end{tabular}

Fonte: Brasil (2017).

A partir da Lei $n^{\circ}$ 13.540/2017, os recursos oriundos da CFEM passaram a ser distribuídos da seguinte forma: 10\% para a União ( dos quais 7\% à ANM, 1\% ao Fundo Nacional de Desenvolvimento Científico e Tecnológico - FNDCT, 1,8\% ao Centro de Tecnologia Mineral - CETEM e 0,2\% ao Instituto Brasileiro do Meio Ambiente e dos Recursos Naturais Renováveis - IBAMA); 15\% para o Distrito Federal e os Estados onde ocorrer a produção; 60\% para o Distrito Federal e os Municípios onde ocorrer a produção; $15 \%$ para o Distrito Federal e os Municípios, quando afetados pela atividade de mineração e a produção não ocorrer em seus territórios (Brasil, 2017). Sendo assim, a partir do ano de 2018 alguns municípios brasileiros afetados pela mineração passaram a ter direito a um percentual dos royalties minerais arrecadados pela ANM.

O Decreto $n^{\circ} 9.407$, de 12 de junho de 2018, apresenta todos os critérios técnicos para a apuração e distribuição da CFEM aos municípios beneficiados. Dos $15 \%$ destinados aos municípios afetados, $2 \%$ deste percentual deverá ser repassado ao município produtor que for gravemente afetado pela perda de receita da CFEM (redução na receita a partir de $30 \%$ ) pela 
alteração da Lei $n^{\circ}$ 13.540/2017 (Figura 1). Caso a redução da receita do município produtor não ultrapasse o percentual estabelecido, os $15 \%$ da arrecadação da CFEM será distribuído entre os municípios impactados.

Figura 1. Critérios de distribuição entre os municípios impactados pela mineração conforme o Decreto nº 9.407/2018.

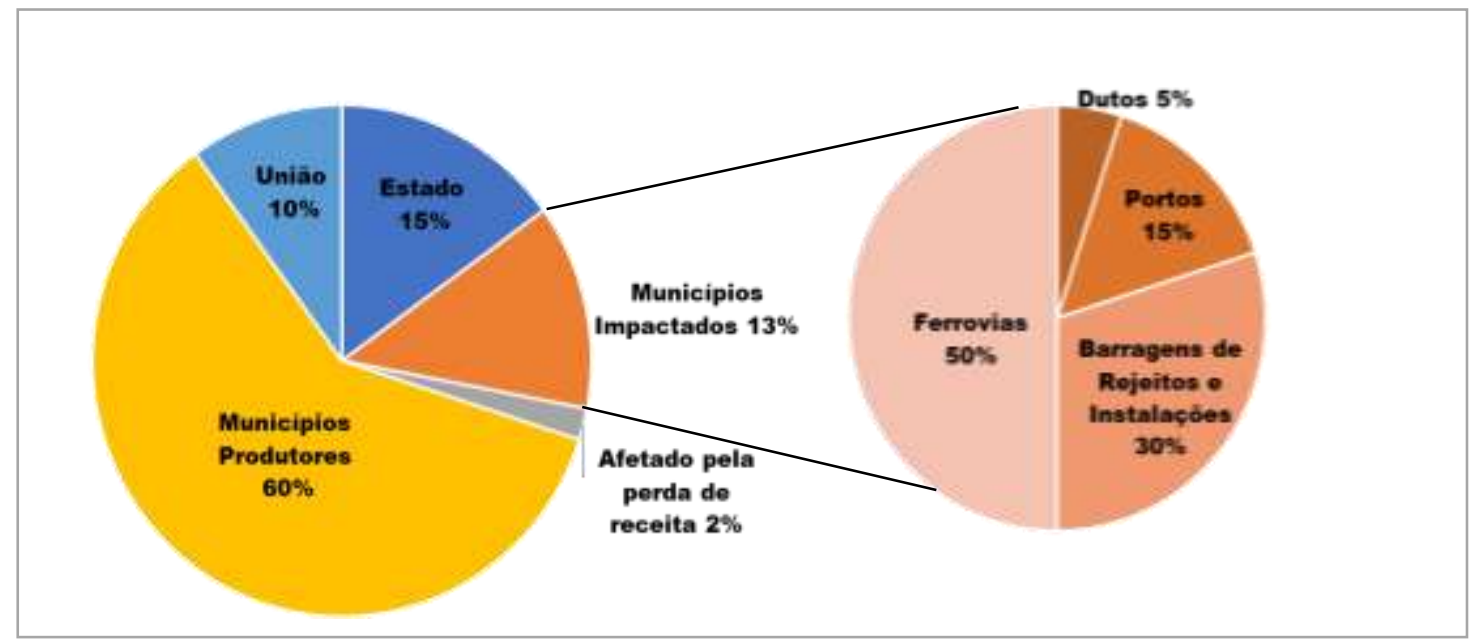

Fonte: Brasil (2018).

O Decreto $n^{\circ}$ 9.407/2018 determinou que para cada substância mineral será realizado o cálculo e o repasse mensal da CFEM aos municípios afetados pela mineração, quando a produção não ocorrer em seus territórios, nos seguintes casos: quando cortados por infraestruturas utilizadas para o transporte ferroviário (50\%) ou dutoviário (5\%) de substâncias minerais; quando afetados pelas operações portuárias de substâncias minerais em seus territórios (15\%); e quando, em seus territórios, estiverem localizadas as pilhas de estéril, as barragens de rejeitos, as instalações de beneficiamento de substâncias minerais (30\%), conforme estabelecido no plano de aproveitamento econômico dos empreendimentos minerários (Brasil, 2018).

A Resolução ANM n n $^{\circ}$, de 2 de abril de 2019, alterada pela Resolução ANM n 25, de 11 de fevereiro de 2020, disciplinou o disposto nesse Decreto. Estabeleceu que o cálculo e o repasse da CFEM aos municípios afetados serão efetuados mensalmente pela ANM, que revisará anualmente os dados que afetem os cálculos das compensações devidas aos municípios afetados pela mineração e divulgará no seu portal eletrônico, até o dia 15 de abril de cada ano, a lista dos municípios beneficiados pelo Decreto $n^{\circ}$ 9.407, de 2018. A inclusão no rol dos municípios afetados ou a correção das informações utilizadas para o cálculo da CFEM poderá ser requerida à ANM até 25 de abril, e a lista final será divulgada em seu portal eletrônico até o dia 9 de maio de cada ano.

A aplicação dos recursos da CFEM não é especificada por lei, a qual apenas proíbe sua destinação em pagamento de dívidas ou no quadro permanente de pessoal da União, dos Estados, Distrito Federal e dos Municípios, e recomenda sua aplicação em projetos, que direta ou indiretamente revertam em prol da comunidade local, na forma de melhoria da infraestrutura, qualidade ambiental, saúde e educação. Além disso, no intuito de reduzir a dependência pela atividade de mineração, a Lei n ${ }^{\circ}$ 13.540/2017 recomenda que o Distrito Federal, os Estados e os Municípios destinem pelo menos 20\% de suas parcelas para atividades relativas à diversificação econômica, ao desenvolvimento mineral sustentável e ao desenvolvimento científico e tecnológico (Brasil, 2017). 


\section{Metodologia}

\section{1 Área de Estudo}

O estado do Pará destaca-se em nível nacional por ter a economia mineral como parte significativa de seu Produto Interno Bruto (PIB). Atualmente, este estado apresenta 22 municípios impactados pela atividade de mineração (Quadro 2), os quais passaram a receber royalties minerais conforme o estabelecido no Decreto nº 9.407/2018 (ANM, 2021).

Quadro 2. Lista dos municípios afetados pela atividade de mineração beneficiários de parcela da CFEM no estado do Pará referente ao mês de abril de 2021.

\begin{tabular}{|l|l|l|}
\hline \multicolumn{3}{|c|}{ Municípios Paraenses Afetados } \\
\hline Abaetetuba & Eldorado Do Carajás & Parauapebas \\
Acará & Ipixuna Do Pará & Santa Luzia Do Pará \\
Água Azul do Norte & Itaituba & Santana Do Araguaia \\
Almeirim & Marabá & São Félix Do Xingu \\
Aveiro & Moju & São Geraldo Do Araguaia \\
Barcarena & Oeiras do Pará & Tomé-Açu \\
Bom Jesus do Tocantins & Ourilândia do Norte & \\
Cumaru Do Norte & Palestina do Pará & \\
\hline
\end{tabular}

Fonte: ANM (abril/2021).

Nesse estudo foi escolhido o município de Barcarena (Figura 2), localizado próximo da cidade de Belém, por ser um importante centro industrial produtor de alumínio e caulim, e apresentar o maior porto do estado do Pará: Vila do Conde.

Figura 2. Mapa de localização do município de Barcarena no estado do Pará.

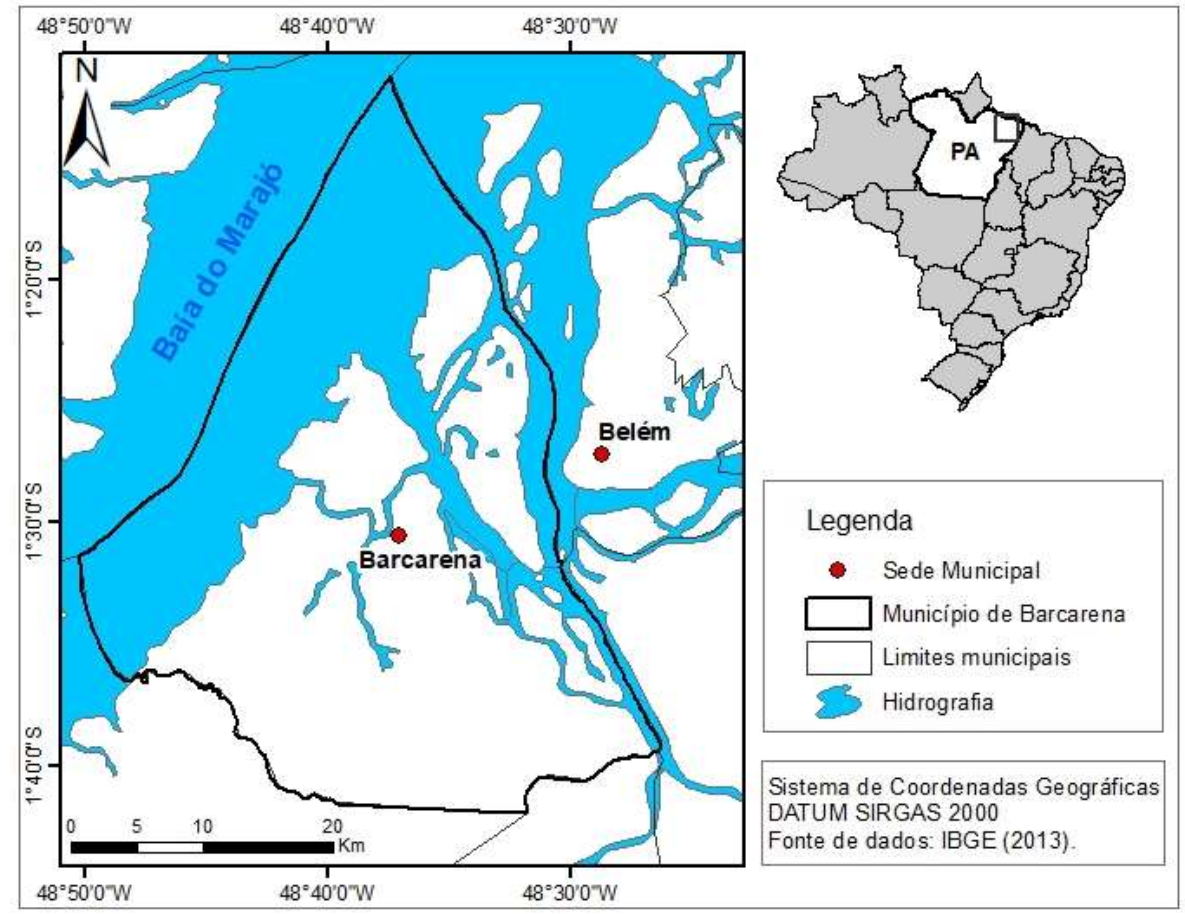

Fonte: Autores (2021). 
O município de Barcarena apresenta área de 1.310,33 km² e população estimada em 124.680 mil habitantes (IBGE, 2019), destaca-se pela infraestrutura e logística estabelecida em função da atividade minerária e metalúrgica, sendo de grande relevância para a balança comercial mineradora do estado, em função de sua proximidade com a capital do estado, Belém, e com o oceano Atlântico, que facilita o escoamento da produção para o mercado externo.

No Complexo Industrial de Barcarena ocorrem operações portuárias e escoamento de minérios oriundos de vários empreendimentos minerários, onde destacam-se as instalações das empresas estrangeiras Hydro e Imerys (Figura 3). A Usina Hidroelétrica de Tucuruí, no rio Tocantins, é responsável pelo abastecimento desse complexo através da Subestação Vila do Conde da Eletronorte.

Figura 3. Complexo Industrial de Barcarena.

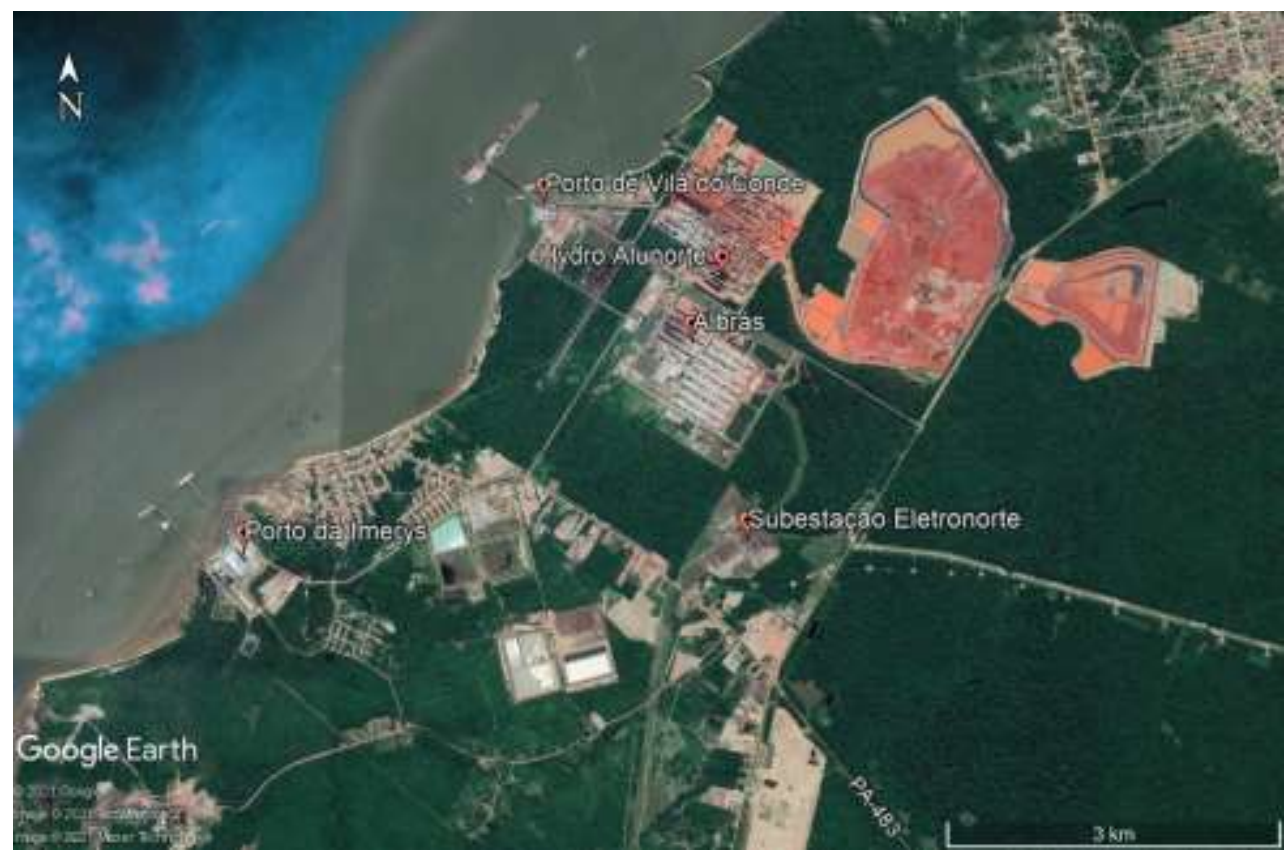

Fonte: Elaborado no Google Earth Pro (2021).

\subsection{Coleta e Análise de dados}

Esta pesquisa trata-se de um estudo de caso realizado por meio de pesquisa bibliográfica, análise da legislação brasileira e dos valores da CFEM distribuídos aos municípios afetados pela mineração disponíveis no site da ANM, no período de abril de 2019 a abril de 2021, tendo como objeto da investigação o município de Barcarena.

O pagamento dos valores da CFEM por substância mineral é realizado mensalmente pela ANM aos municípios afetados. Estes valores estão diretamente ligados ao preço das substâncias minerais no mercado e a produtividade das empresas mineradoras, quanto maior a quantidade de minério produzido, maior será o valor arrecadado e posteriormente distribuído aos entes federativos. Portanto, não existe previsão de quanto um determinado município receberá mensalmente.

Mensalmente será aplicado o percentual do fator de distribuição que o município tem direito para cada substância, estes valores poderão ser acompanhados pelo site da ANM (http://www.anm.gov.br/assuntos/cfem-municipiosafetados/valores-distribuicao) com as respectivas memórias de cálculo e nota técnica explicativa. O município não produtor que apresentar estruturas validadas pela ANM, será elegível para receber como afetado, por meio de análise dos Relatórios Anuais de Lavra dos empreendimentos situados no município. Além disso, um mesmo município pode receber o percentual da CFEM correspondente ao de afetado para uma substância mineral (15\%) e de município produtor para outra $(60 \%)$. 
A atualização da lista de municípios afetados beneficiários e municípios gravemente afetados do ano de 2021, além dos critérios do valor de distribuição definidos na legislação, não foram divulgados no site da ANM no prazo determinado pela Resolução ANM no 6/2019 (até o dia 9 de maio). Sendo assim, utilizou-se como referência os dados disponíveis até o mês de abril de 2021, dos municípios paraenses afetados pela mineração validados pela ANM.

Os dados da CFEM coletados no site da ANM foram organizados em um banco de dados no software Excel 2016 para elaboração de tabelas e gráficos. Os mapas foram realizados em ambiente de Sistema de Informação Geográfica - SIG, nos softwares ArcGis 10.5 e Google Earth Pro, projetados no Sistema de Coordenadas Geográficas - DATUM SIRGAS 2000.

\section{Resultados e Discussão}

\subsection{Distribuição de royalties da mineração ao município de Barcarena}

Desde a publicação do Decreto $\mathrm{n}^{\circ}$ 9.407/2018, os valores referentes aos 15\% da CFEM destinados aos municípios afetados foram guardados em um fundo até o estabelecimento dos critérios e parâmetros de distribuição. A ANM determinou que o município de Barcarena se enquadra nos critérios de repartição dos recursos da CFEM, fazendo parte tanto do rol dos municípios afetados pelas operações portuárias em seus territórios, quanto pela presença de minerodutos. Os royalties minerais distribuídos a esse município paraense encontram-se na Figura 4, observa-se que Barcarena recebeu o total de R \$3.840.920,74 de compensação financeira no período analisado.

Figura 4. Valores de distribuição mensal da CFEM (R\$) ao município de Barcarena.

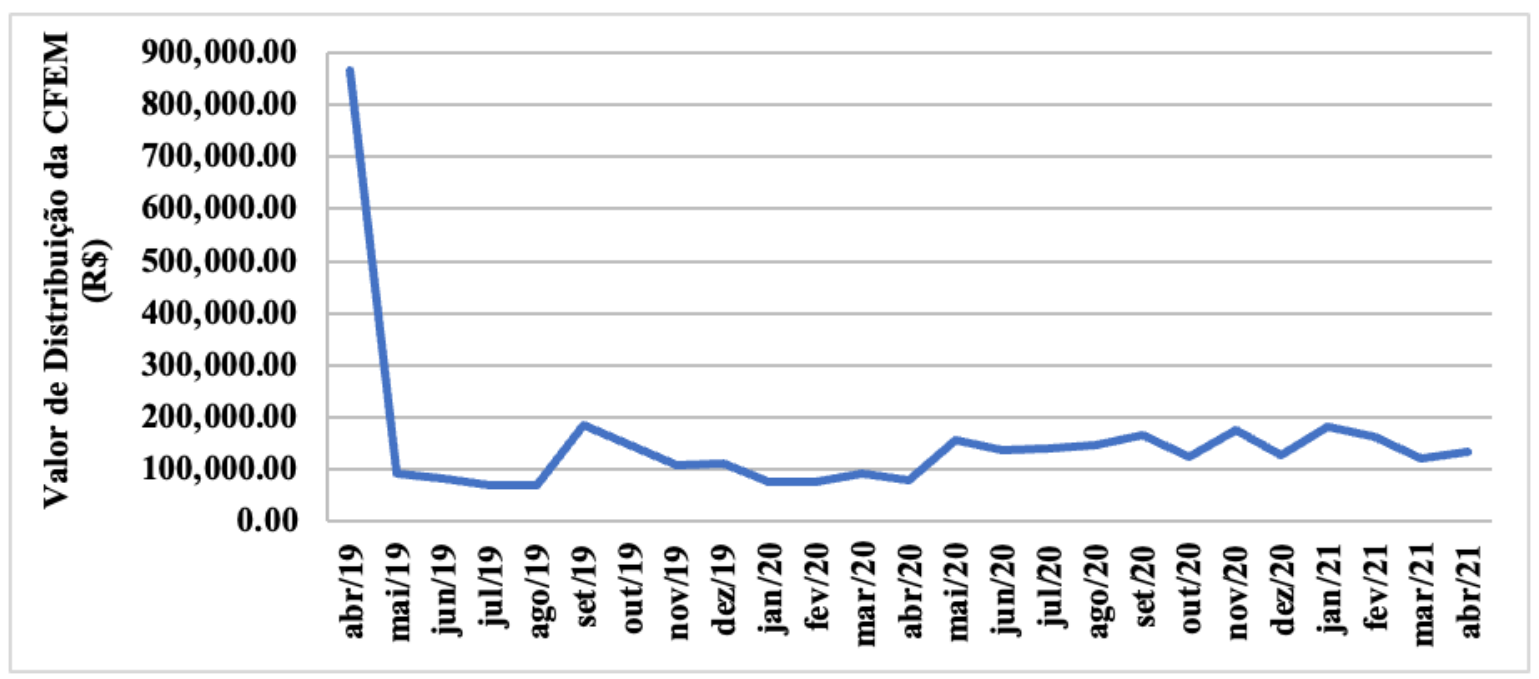

Fonte: Autores, adaptado da ANM (2021).

Os valores represados desde junho de 2018 foram repassados somente no mês de abril de 2019 à Barcarena, apresentando a maior receita da CFEM recebida pelo município no período analisado ( $\mathrm{R} \$ 866.761,53$ ). Nos meses posteriores, os royalties minerais passaram a ser distribuídos mensalmente de acordo com os critérios e as regras estabelecidas pela ANM. A CFEM devida ao município de Barcarena por ser afetado por operações portuárias de embarque e desembarque de minérios provenientes de outros municípios, refere-se as seguintes substâncias minerais: argila, caulim, minério de alumínio, minério de cobre, minério de estanho, minério de ferro, minério de manganês e minério de zinco. E a compensação devida pela presença de minerodutos em seus territórios, refere-se à operação de dois minerodutos de caulim e um mineroduto de minério de alumínio (bauxita).

Dentre as substâncias minerais que tem logística no município de Barcarena, temos a bauxita produzida pela empresa norueguesa Norsk Hydro em Paragominas. Este minério de alumínio é transportado de Paragominas através de um mineroduto 
que abastece a usina de Barcarena, onde passa por processos de transformação mineral, sendo posteriormente embarcado em navios no porto de Vila do Conde, com destino ao mercado nacional e sobretudo aos mercados externos. Os processos industriais de transformação mineral no município são intensivos no consumo de energia, envolvem a produção de alumina pela fábrica da Alunorte (Alumina do Norte do Brasil S.A.) e de alumínio pela empresa Albrás (Alumínio Brasileiro S.A.).

$\mathrm{O}$ mineroduto que transporta o minério de alumínio de Paragominas à Barcarena passa por vários municípios e importantes rios da região ao longo de seu trajeto, como o Rio Capim, Rio Acará-Mirim, Rio Acará e o Rio Moju (Figura 5), fragmentando diversas propriedades e terras de comunidades tradicionais, como a dos quilombolas do Rio Moju, que vivem em constante risco de contaminação por vazamento.

Figura 5. Municípios impactados pela logística de escoamento da bauxita produzida no município de Paragominas.

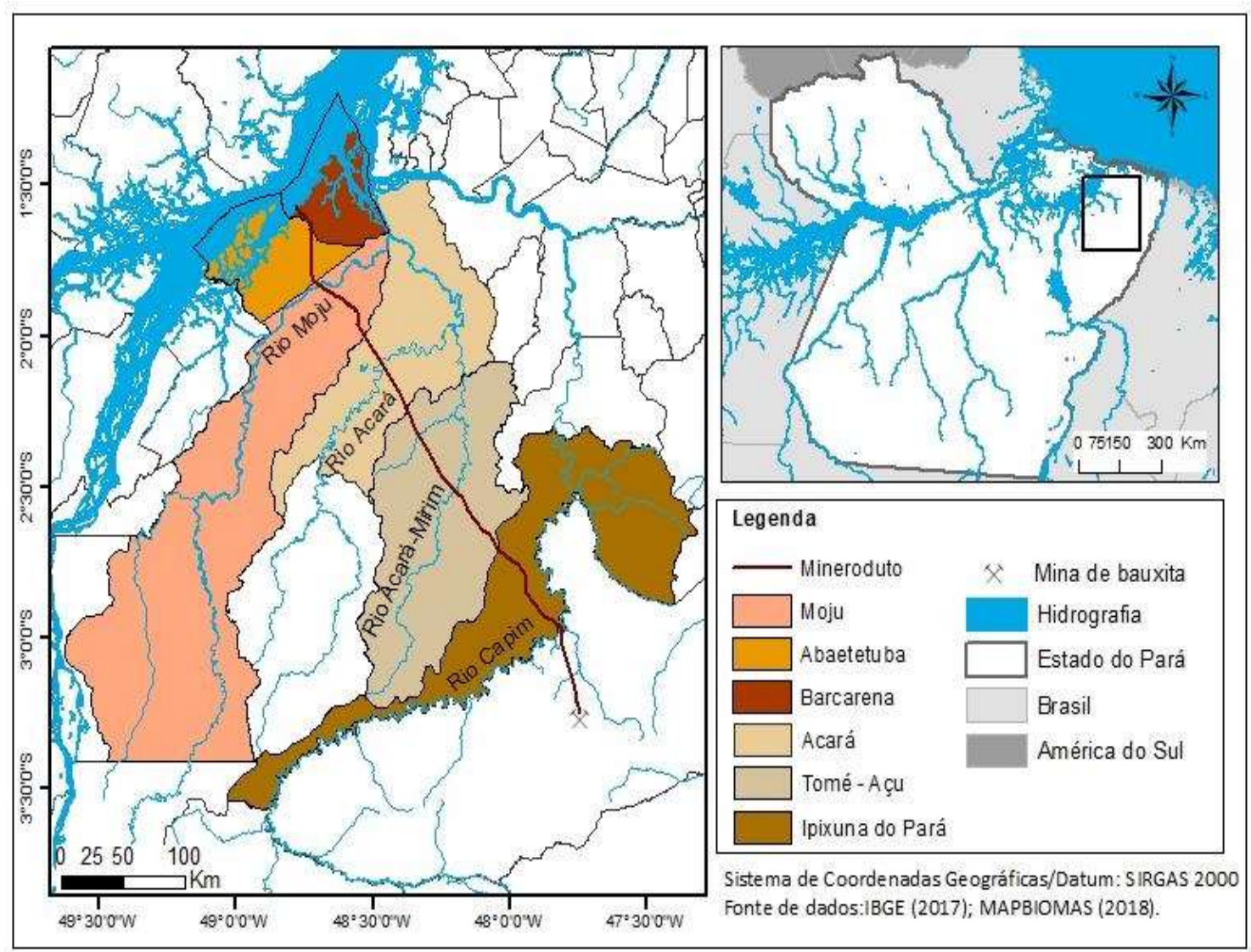

Fonte: Autores (2021).

A Tabela 1 apresenta o valor distribuído da CFEM a cada município afetado no mês de janeiro de 2021, conforme o percentual de distribuição do minério de alumínio estabelecido pela ANM. Na determinação do percentual estabelecido na categoria mineroduto, a ANM considera a extensão territorial atravessada pelo duto em cada município afetado, portanto, o município Barcarena recebe o menor percentual desse grupo. Em contrapartida, na categoria de operações portuárias os royalties minerais distribuídos a Barcarena são mais significativos, o que faz o município despontar como o maior beneficiado da CFEM dentre os municípios impactados pela exploração de bauxita em Paragominas. 
Tabela 1. Valor da distribuição da CFEM (R\$) referente ao minério de alumínio ao município de Barcarena -janeiro de 2021.

\begin{tabular}{lrrcrr}
\hline Municípios afetados & Mineroduto (R\$) & $\begin{array}{r}\text { Distribuição } \\
\text { por substância }\end{array}$ & $\begin{array}{c}\text { Operações } \\
\text { portuárias (R\$) }\end{array}$ & $\begin{array}{c}\text { Distribuição } \\
\text { por substância }\end{array}$ & \multicolumn{1}{c}{ Total } \\
\hline Abaetetuba & $11.552,09$ & $9,30 \%$ & - & - & $11.552,09$ \\
\hline Acará & $22.782,08$ & $18,34 \%$ & - & - & $22.782,08$ \\
\hline Barcarena & $9.131,85$ & $7,35 \%$ & $101.643,73$ & $27,27 \%$ & $110.775,58$ \\
\hline Ipixuna do Pará & $24.434,41$ & $19,66 \%$ & - & - & $24.434,41$ \\
\hline Moju & $17.879,91$ & $14,39 \%$ & - & - & $17.879,91$ \\
\hline Tomé- Açu & $38.474,03$ & $30,96 \%$ & - & - & $38.474,03$ \\
\hline Total & $\mathbf{1 2 4 . 2 5 4 , 3 7}$ & $\mathbf{1 0 0 \%}$ & & & \\
\hline
\end{tabular}

Fonte: ANM (jan/2021).

\subsection{Análise da contribuição dos royalties minerais no desenvolvimento local}

O município de Barcarena apresenta destaque no estado do Pará em função dos projetos industriais e atividades portuárias em seu território, onde a localização do porto de Vila do Conde é estratégica para que o minério beneficiado chegue ao mercado nacional e internacional. Este município tem apresentado um crescimento econômico nos últimos anos, registrou PIB (Produto Interno Bruto) de R $\$ 4.737 .587$ em 2018, o $8^{\circ}$ maior PIB do estado do Pará, e ficou na $7^{\circ}$ posição em termos de PIB per capita com R \$38.739,32, oriundo principalmente do setor de indústria e de serviços (FAPESPA, 2020).

Em contrapartida, a instalação de empresas de transformação mineral ocasionou um intenso crescimento populacional e vem causando diversos problemas socioambientais no município. Este crescimento populacional, ocasionado pela possibilidade de empregos no distrito industrial, foi desproporcional ao planeamento urbano municipal, potencializando os problemas sociais no município, como a falta de serviços de saneamento adequados, ausência de políticas habitacionais, desgaste das vias públicas devido ao intenso tráfego de caminhões transportando minérios e outros produtos destinados ao embarque no Porto de Vila do Conde, além de pressionar a demanda por serviços públicos como educação, saúde e segurança.

De acordo com o Ranking da ABES (Associação Brasileira de Engenheiros de Saneamento), no ano de 2017, Barcarena foi classificado como o pior município brasileiro de grande porte (acima de 100 mil habitantes), em termos de abastecimento de água; coleta e tratamento de esgoto; coleta e destinação adequada de resíduos sólidos. O estudo relata ainda que o município apresentou cerca de 102 internações médicas, a cada 100 mil habitantes, por doenças causadas pela falta de saneamento básico (ABES, 2018).

Além disso, nos últimos anos, ocorreram vários desastres ambientais no município de Barcarena, que comprometeram sobretudo os recursos hídricos da região, dentre eles vazamentos de caulim e de rejeitos de bauxita das indústrias locais, tendo como principais atingidos as famílias de ribeirinhos e comunidades tradicionais que mantêm relação direta com o meio ambiente (Barcelos \& Cordeiro).

Diante do exposto, observa-se que os impactos socioeconômicos e ambientais oriundos de grandes projetos de mineração não se restringem aos municípios onde ocorrem a extração do minério, estes também recaem nos municípios de entorno, afetados pela logística destas atividades na Amazônia Brasileira. Sendo assim, os municípios afetados foram recentemente incluídos na repartição dos royalties minerais, em razão da aprovação da Lei 13.540/2017, tendo em vista que essas receitas se destinam a reparar e minimizar os impactos locais oriundos da exploração mineral e futuro esgotamento da atividade de mineração.

As receitas da CFEM recebidas pelo município de Barcarena são notadamente menores que as recebidas pelos principais municípios produtores de minérios do estado do Pará, os quais recebem a maior parcela da arrecadação da CFEM 
(60\%), apresentando um menor potencial de contribuição na promoção do desenvolvimento local. Nos anos analisados, o valor repassado de royalties minerais à prefeitura municipal não correspondeu nem a $1 \%$ de sua Receita Total, entretanto, a inclusão desse município no rol de beneficiados da compensação financeira é considerada uma conquista do movimento municipalista, o qual vinha reivindicando esse direito há muitos anos.

A opção mais razoável para a aplicação destes recursos seria na melhoria da qualidade de vida da comunidade local, assegurando no futuro, novas formas econômicas de sobrevivência e sustentabilidade do município de Barcarena, tendo em vista que os recursos minerais são finitos. Vale ressaltar que o estabelecimento de uma gestão eficiente no uso dos royalties minerais, com mecanismos de controle, distribuição e gestão sustentáveis é de vital importância para que haja melhorias socioeconômicas e ambientais nos municípios afetados (Rodrigues \& Rodrigues, 2019; Sakamoto, Rodrigues \& Alves, 2020).

O processo de desenvolvimento de um município, que lhe permite superar os seus problemas sociais e mobilizar suas potencialidades econômicas, depende de sua organização social e política para a tomada de decisões. Observa-se que a sociedade não tem participação ativa nas tomadas decisões, tendo que aceitar as propostas formuladas pelo governo estadual e, principalmente municipal. Falta estudo técnico especializado que possa embasar a tomada de decisão da gestão local, para o investimento em projetos sociais e em prol do meio ambiente que visem principalmente a melhoria da qualidade de vida da população local. Além disso, há pouca transparência em relação às políticas e destinações que estão sendo dadas aos recursos oriundos da CFEM no município de Barcarena, não sendo possível realizar o seu rastreamento nas despesas realizadas pela prefeitura municipal no período analisado.

O município deve apresentar um plano estratégico para o desenvolvimento local, tendo em vista que a expectativa é que futuramente ocorra a atração de novos investimentos do setor mineral na região. Cabe notar que a transformação mineral é a atividade dentro do setor mineral que gera o maior quantitativo de empregos, o que reforça a necessidade de políticas visando à verticalização da produção mineral do alumínio e do caulim na região, com a finalidade de fabricação de produtos para consumo. A produção de energia é fundamental para a cadeia produtiva do alumínio, há muitos países que possuem grandes reservas de bauxita, mas não possuem a mesma oferta energética da nossa região para a operacionalização dessa cadeia, o que favorece a realização desta atividade no município, já que o alumínio é o segundo metal de maior demanda no mundo.

No entanto, a maioria dos municípios da Amazônia brasileira permanece com as mesmas bases extrativistas, ou seja, exportador de minério bruto ou beneficiado, sem valor agregado e inovação tecnológica, onde o desenvolvimento é pouco percebido pela população local. Destarte, torna-se fundamental o planejamento e execução de políticas que auxiliem na diversificação econômica do município como investimento na pesca, agricultura e turismo, além do fomento a verticalização das cadeias produtivas minerais para promoção do desenvolvimento industrial e maior geração de emprego e renda, para que assim o município possa avançar significativamente de acordo com suas potencialidades.

\section{Conclusão}

Assim como em outros municípios da Amazônia brasileira, as atividades minerárias em Barcarena provocaram transformações sociais e ambientais. A dimensão econômica se mostrou positiva com o PIB per capita elevado devido as atividades industriais no município, entretanto, este não é indicativo de desenvolvimento. O município apresenta problemas socioambientais devido ao aumento populacional e pela ocorrência de desastres ambientais oriundos das atividades presentes no distrito industrial e das atividades portuárias, as quais são de grande relevância para o desenvolvimento local e regional.

Durante o período de dois anos, o município de Barcarena recebeu R \$ 3.840.920,74 de compensação financeira, por ser afetado pela presença de minerodutos e operações portuárias em seu território. Estes valores são pouco significativos se comparados aos recebidos pelos principais municípios produtores de minério na Amazônia brasileira, entretanto, podem ser aplicados de forma estratégica no seu desenvolvimento local, através de sua aplicação na melhoria de serviços públicos 
municipais, da qualidade ambiental e da infraestrutura local, sobretudo do seu saneamento básico, o qual já foi classificado pela ABES como o pior dentre os municípios brasileiros de grande porte.

Além da disponibilidade de receitas, o desenvolvimento local depende da vontade política para empregar esses recursos de uma forma efetiva, a qual possibilite melhorias nos indicadores socioeconômicos e ambientais deste município que é impactado pela atividade da mineração. As comunidades locais demandam por políticas públicas e programas de investimentos não somente para a implantação de infraestrutura para as atividades industriais, mas também que se preocupem com o seu desenvolvimento socioeconômico, enfatizando a necessidade de uma maior transparência e rastreabilidade na aplicação dos royalties minerais por parte dos governantes locais. Portanto, os recursos da CFEM podem ser um importante instrumento para promoção do desenvolvimento socioeconômico dos municípios afetados pela mineração, sendo necessário a realização de mais estudos sobre a temática, considerando as potencialidades de cada município beneficiado.

\section{Agradecimentos}

Este trabalho foi realizado com apoio da Coordenação de Aperfeiçoamento de Pessoal de Nível Superior - Brasil (CAPES) - Código de Financiamento 001.

\section{Referências}

Agência Nacional de Mineração (ANM) (2021). CFEM Municípios Afetados. https://www.gov.br/anm/pt-br/assuntos/arrecadacao/apuracao-municipiosafetados

Amaral, M. V. B., \& Hauradou, G. R. (2020). O discurso da/sobre a mineração na Amazônia Brasileira: Sítio de exploração e fetiche. Organon, 35(70), 1-17. https://doi.org/10.22456/2238-8915.103593

Associação Brasileira de Engenharia Sanitária e Ambiental (ABES) (2018). Ranking ABES da Universalização do Saneamento: referência 2017. http://abesdn.org.br/?p=18536

Barcelos, G. J, N., Lage, J. R. D., \& Cordeiro, J. S. (2020). Caracterização das barragens de rejeitos de minas do Brasil. Research, Society and Development, 9 (3), e135932478. https://doi.org/10.33448/rsd-v9i3.2478

Brasil. Decreto $n^{\circ} 9407$, de 12 de junho de 2018. (2018). Regulamenta o disposto no inciso VII do $\S 2^{\circ}$ e no $\S 5^{\circ}$ do art. $2^{\circ}$ da Lei ${ }^{\circ} 8.001$, de 13 de março de 1990.

Brasil. Lei $n^{o}$ 13.540, de 18 de dezembro de 2017. (2017) Dispõe sobre a Compensação Financeira pela Exploração de Recursos Minerais (CFEM).

Carmo, E. D. (2020). Contrainformação e conhecimento emancipatório como práticas educativas no enfrentamento da economia de desastres da mineração em Barcarena (PA). Revista Brasileira de História \& Ciências Sociais, 12(23), 177-195.

Dotsenko, E., \& Ezdina, N. (2018). Sustainable subsoil use as a factor of innovative development of mining region. In E3S Web of Conferences (Vol. 41, p. 04048). EDP Sciences.https://doi.org/10.1051/e3sconf/20184104048

Fundação Amazônia de Amparo a Estudos e Pesquisas (FAPESPA). (2020). Relatório PIB municipal 2018. http://www.fapespa.pa.gov.br/produto/contasregionais/263?\&mes=\&ano=2020

Hauradou, G. R., \& Amaral, M. V. B. (2019). Mineração na Amazônia Brasileira: aspectos da presença e avanço do capital na região. Revista de Políticas Públicas, 23(1), 402-420.http://dx.doi.org/10.18764/2178-2865.v23n1p402-420

Hazeu, M. T., \& Rodrigues, J. C. (2019). Capitalismo financeirizado e acumulação por despossessão na Amazônia: a mineradora Imerys em Barcarena, Nordeste do Pará. Revista Científica Foz, 2(1), 86-119.

Instituto Brasileiro de Geografia e Estatísticas (IBGE) (2019). População residente no Brasil e unidades da federação com data de referência em $1^{\circ}$ de julho de 2019. https://agenciadenoticias.ibge.gov.br/media/com_mediaibge/arquivos/42ff76cf13a382a709c1ba14214b8612.pdf.

Karidio, I., \& Talbot, D. (2020). Controversy in mining development: a study of the defensive strategies of a mining company. Journal of Sustainable Finance \& Investment, 10(1), 18-43. https://doi.org/10.1080/20430795.2019.1657315

Lemos, M. A. Q., \& Pimentel, M. A. S. (2021). Mineração e desastres ambientais com rejeitos de bauxita e caulim no município de Barcarena-Pará-BrasilAmazônia. Territorium, (28 (I)), 137-156. https://doi.org/10.14195/1647-7723_28-1_8

Martins, W. B. R. (2020). Restauração de ecossistemas degradados pela mineração na Amazônia Oriental. Tese (Doutorado em Ciências Florestais) Universidade Federal Rural da Amazônia, Belém,140 f. 
Research, Society and Development, v. 10, n. 9, e9710917670, 2021

(CC BY 4.0) | ISSN 2525-3409 | DOI: http://dx.doi.org/10.33448/rsd-v10i9.17670

Medeiros, G. R. N., Medeiros, M. V. B., \& Medeiros, L. F. (2018). Gestão do Território: análise econômica da mineração nos municípios da Amazônia Oriental paraense (2010 a 2017). InterEspaço: Revista de Geografia e Interdisciplinaridade, 4(12), 227-251. http://dx.doi.org/10.18764/24466549.v4n12p228-252

Nazaré, M. L., Nascimento, P. M. R., \& Penha, R. S. (2019). Grandes Projetos em Barcarena-Pa: Impactos Socioambientais Causados Pelas Atividades da Hydro Alunorte. Revista do Instituto Histórico e Geográfico do Pará, 5(02). http://dx.doi.org/10.17648/ihgp.v5i02.130

Pereira, E. J. D. A. L., Ribeiro, L. C. S., Freitas, L. F. S., \& Pereira, H. B. B. (2020). Brazilian policy and agribusiness damage the Amazon rainforest. Land Use Policy, 92, 104491.https://doi.org/10.1016/j.landusepol.2020.104491

Rodrigues, A. C., \& Rodrigues, S. B. (2019). Riqueza mineral, instituições fracas e clientelismo: a maldição dos recursos naturais nos governos locais. Revista de Contabilidade e Organizações, 13, e153089-e153089. https://doi.org/10.11606/issn.1982-6486.rco.2019.153089

Sakamoto, A. R.., Rodrigues, R. M. M., \& Alves, K. C. S. (2020). O novo regulamento do código de mineração brasileiro: Impactos na captação de investimentos para a indústria do ferro. Brazilian Journal of Development, 6(3), 14473-14486.https://doi.org/:10.34117/bjdv6n3-352

Silva, J. M. P., \& Chagas, S. F. P. (2020). Para quem serve o novo código da mineração? ENTRE-LUGAR, 11(21), 209-239. https://doi.org/10.30612/el.v11i21.12056

Siqueira-Gay, J., Sonter, L. J., \& Sánchez, L. E. (2020). Exploring potential impacts of mining on forest loss and fragmentation within a biodiverse region of Brazil's northeastern Amazon. Resources Policy, 67, 101662.https://doi.org/10.1016/j.resourpol.2020.101662 